\title{
МЕНТАЛИЗАЦИЯ ЛЕКСЕМЫ АЛКОНОСТ В РУССКОМ ЯЗЫКЕ
}

В статье рассмотрена, изучена и проанализирована специфика эволюции лексической семантики, заимствованной из греческого языка номинации алконост в русской языковой картине мира.

Цель настоящей статьи - исследовать особенности ментализации заимствованной лексики при ее усвоении русским языком на примере названной номинации, показать специфику смысловых приращений лексемы алконост в соответствующих контекстах бытования

Актуальным является произведенный в рамках исследования компонентный и контекстный анализ экспликации компонентов семного состава рассматриваемой лексемы в русской лингвокультуре. Принципиально новым в работе представляется выявление автором основных направлений развития семантики заимствованных номинаций, относящихся к лексико-семантической группе «фантастические птицы», в русском языке.

В статье сделан вывод о том, что в процессе ментализации исходное значение номинации алконост 'мифологическая женщина-птица' в русской лингвокультуре одновременно развивалось в двух направлениях - 'фантастическая птица-женщина' ('русская фантастическая райская птица') и 'реальная морская птица'. Автором отмечено, что для значения 'фантастическая птица-женщина' характерно сохранение проявлений мифологического антропоцентризма.

На основе контекстов бытования лексемы алконост полученных с помощью метода сплошной выборки при работе с Национальным корпусом русского языка, автором установлено, что в русском языке для исследуемой номинации в большей степени характерна метонимизация (5 вариантов), чем метафоризация (1 вариант). В ходе исследования также выявлен пример омонимии собственное имя Алконост ${ }^{2}$ со значением 'название прибора'.

Материалы исследования получены в ходе работы с русскими словарями разного типа (энциклопедическими, мифологическими, этнолингвистическими, этимологическими, историческими, толковыми, словарями иностранных слов) и Национальным корпусом русского языка

На основе указанных материалов установлено, что на семантику лексемы алконост оказали влияние номинации гамаюн, сирин и жар-птица.

Ключевые слова: лексическая семантика, лексическое значение, ментализация, семантические компоненты, метонимизация, лексема алконост.

\section{MENTALIZATION OF THE LEXEME ALKONOST IN RUSSIAN LANGUAGE}

The article studies and analyzes the specificity of the lexical semantics evolution of borrowed from the Greek language alkonost nomination in the Russian linguistic picture of the world.

The purpose of this article is to study through the given nomination the specificity of the mentalization of borrowed words in case of their assimilation in the Russian language as well as to show the semantic increments characteristics of the lexeme alkonost in the relevant contexts of existence.

The study offers relevant componential and contextual analysis of the seme component expressions in Russian linguistic culture. The author provides a fundamentally new specification of the basic directions of semantics development of borrowed nominations related to the lexico-semantic group "fantastic birds" in Russian.

The article concludes that the initial meaning of alkonost nomination 'mythological woman-bird' during the mentalization process in the Russian linguoculture was developed in two directions at the same time - 'fantastic bird-woman' ('Russian fantastic bird of paradise') and 'real sea bird'. The author noted that the meaning 'fantastic bird-woman' is

Мифологическое мышление, представляющее собой древнейшую неотьемлемую составляющую сознания человека и воплощаемое в мифо- characterized by the keeping of the mythological anthropocentrism manifestations.

Based on the contexts of existence of lexeme alkonost which were obtained using the sampling method through the National Corps of the Russian language, author found that metonymization ( 5 versions) is more common than metaphorization ( 1 version) for the explored nomination in the Russian language. The study also discovered an example of homonymy - proper name Alkonost ${ }^{2}$ with the meaning 'device name'.

The research materials were obtained during the work with different types of Russian dictionaries (encyclopedic, mythological, ethnolinguistic, etymological, historical, explanatory ones, dictionaries of foreign words) and the $\mathrm{Na}$ tional Corps of the Russian language.

Based on these materials, it was found that the semantics of alkonost nomination were influenced by hamayun, sirin and firebird nominations.

Key words: lexical semantics, lexical meaning, mentalization, semantic components, metonymization, lexeme alkonost.

погию, является важной частью национальной картины мира. Оно «представляет собой творение в воображении или с помощью воображения 
иной действительности - субъективной и иллюзорной, служащей не столько для объяснения, сколько для оправдания определенных («священных») установлений, для санкционирования определенного сознания и поведения» [9, с. 15].

Мифологическое мышление оказало большое, но не осознаваемое современными носителями языка, влияние на языковую картину мира. В каждом языке представлены, например, наименования предметов, реально не существующих, но имеющих место в языковом сознании в виде определенной мифологии. Появление номинаций такого типа возможно благодаря тому, что признаки, составляющие их основу, могут быть не только не существенным или случайным, но даже нереальным.

Такая неразделенность реально существующего и сверхъестественного мира в рамках мифологического мышления привела к появлению образов фантастических птиц в русской лингвокультуре.

В этнолингвистическом словаре «Славянские древности" под редакцией Н. И. Толстого дается следующее определение понятию птицы: «особая группа животных персонажей, представленных в народной культуре как собирательно, так и индивидуально и отличающихся от других групп животных способностью летать (а от летающих насекомых - неспособностью ползать)» [16, c. 345]. Птицы фантастические в основном встречаются в фрольклоре, книжной традиции, реже в поверьях. Нередко лексемы для их номинации заимствовались из других языков.

Освоенным заимствованием можно считать такое слово, которое приспособилось фонетико-графически и морфологически к системе заимствующего языка и адаптировалось семантически в ней. На наш взгляд, среди семантических процессов, которые могут происходить с ассимилирующимися и освоенными иноязычными словами, особый интерес представляют случаи, когда значение лексемы в заимствующем языке далеко отходит от ее исходной семантики в языке-источнике.

Вслед за Е. М. Верещагиным, под ментализацией заимствованных слов (или семантическим расхождением между заимствованным словом и его «этимоном») будем понимать «переход с понятийного на более сложный и разветвленный фоновый уровень, перевод не исходного слова-термина, а какой-либо семантической доли из его смыслового объема» [4, с. 111]. Данная статья ставит своей целью проанализировать ментализацию заимствованной лексики при ее усвоении русским языком на примере номинации фантастической птицы алконост.

Материалы исследования получены в ходе работы с дефинициями, извлеченными из русских словарей разного типа (энциклопедических, мифологических, этнолингвистических, этимологических, исторических, толковых словарей и словарей иностранных слов), и данными Основного подкорпуса Национального корпуса русского языка (цитирование опирается на материалы НКРЯ).
Ведущими являются следующие методы исследования: метод анализа словарных дефиниций при работе с лексикографическими источниками, метод компонентного анализа значения слова при работе с лексикографическими источниками, метод сплошной выборки при работе с НКРЯ для отбора материала исследования, метод контекстного анализа смыслов лексемы при работе с контекстами бытования лексем, общенаучные теоретические методы (метод наблюдения, описания, обобщения).

В ходе исследования нами было обнаружено, что для лексемы алконост характерна широкая включенность в состав словника лексикографических изданий различного типа. В русских энциклопедических (2 словаря), мифологических (2 словаря), этнолингвистических (4 словаря), этимологических (2 словаря), исторических (7 словарей), толковых (1 словарь) словарях и словарях иностранных слов (4 словаря) было найдено 22 дефиниции данного слова [2, с. 376], [1, с. $443],[11$, c. 50$],[10$, c. 35$],[17$, c. 100$],[27$, c. 25$]$ $[14$, c. $32-33],[15$, c. $20-21],[25$, c. 71$],[27$, c. 76$]$ $[18$, c. 24$],[222$, c. 6$],[8$, c. 17$],[19$, c. 29], [20], $[5$, c. $11-12],[23$, c. 11$],[21$, c. 94$],[13$, c. 36$],[7$, c. 23], [3, с. 25], [6, с. 17]. Данные Национального корпуса русского языка (Основной подкорпус) показывают обратную ситуацию частотности для лексемы алконост: она встретилась только в 30 документах, при этом всегда употреблялась без кавычек и пояснений: "Они изображали райских птиц Сирина, Алконаста и Гамаюна, <...>. [П. И. Мельников-Печерский. В лесах. Книга вторая (1871-1874)]» [12].

Слово алконост восходит к древнерусскому (старославянскому по Н. М. Шанскому) языку и представляет собой фонетическое и морфологическое преобразование на русской почве древнерусского выражения, включавшего греческое слово: алкионъ есть птица [24] [28, с. 76]. В словарных статьях фиксируются следующие орфографо-графические варианты оформления лексемы в русском языке: алкион (алкиона) алцион - алкуонес - алконос - алконост. В «Этимологическом словаре русского языка» М. Фасмера указывается, что номинация алконост становится частотной с XV В., из Палеи XVI В. она переходит в азбуковники [25, с. 71]

Заимствована же русским языком лексема алконост была примерно в XI в. напрямую из греческого языка, в котором первоначально имела значение 'зимородок', позже трансформировавшееся в название мифологической птицы $[15$, с. $20-21],[25$, с. 71$],[28$, с. 76$]$. Это значение номинации базируется на древнегреческом этиологическом мифе, который мы можем примерно восстановить, опираясь на словари. Так, царица Алкиона была обращена в зимородка (алкиона) Зевсом в наказание за их с мужем тщеславие и богохульство или Фетидой в награду за супружескую преданность и любовь. В облике морской птицы Алкиона могла успокаивать море и чудесно петь. 
В структуре мифологического значения слова алконост мы выделили, по данным русских энциклопедических, этнолингвистических и мифологических словарей, следующие семантические компоненты: 'источник сюжета', 'причина превращения в птицу', 'вид птицы', 'обозначение индивидуального объекта', 'гендер (феминность)', 'семья', 'социальная характеристика', 'особенности поведения', 'способности', 'локализация', 'связь с божествами'. В мифах номинация алконост с точки зрения этики оценивалась двойственно, что отмечается в «Большой энциклопедии. Словаре общедоступных сведений по всем отраслям знания» под редакцией С. Н. Южакова, где приводится два варианта причины трансформации женщины в птицу (ее наказание или награда) [2, с. 376] Постепенно в греческой культуре наблюдается сужение мифологического компонента значения данного слова вплоть до фиксации исключительно самого факта волшебного превращения. Как номинация мифологической птицы лексема алконост также входит в состав идиомы алкионины (алкионовы, алконостовы) дни со значением 'штиль и тихая погода', которое базируется на семах исходного значения 'морская' и 'положительно влияющая на погоду' [2, с. 376], [15, с. 20-21].

В русском языке номинация алконост толкуется как: 1) собственно русская фонтастическая птица, отличная по своим характеристикам от мифологического алкиона/Алкионы; 2) реальный вид морской птицы (зимородок), относящийся к определенному семейству. На наш взгляд оба значения возникли на базе редуцированного мифа.

Итак, произошел определенный семантический сдвиг в структуре значения лексемы. Вместе с древнегреческим мифом о птице были утрачены семы 'причина превращения в птицу', 'обозначение индивидуального объекта', 'семья', 'особенности поведения', 'связь с божествами'. Как следствие идиоматическое выражение алкионины (алконостовы) дни перестает употребляться. Семантические компоненты 'источник сюжета', 'гендер (феминность)', 'социальная характеристика', 'локализация', 'оценка', 'количественная характеристика' в той или иной степени трансформировались, при этом сохранив связь с древнегреческим мифом об Алкионе. Отметим, что сема 'способности' ('управление ветрами и погодой'; 'чудесный голос, заставляющий забыть обо всем') осталась практически неизменной. Положительная этическая оценка наименования алконост стала причиной появления в структуре его значения аналогичной эстетической оценки, при этом происходит утрата отрицательного варианта этической оценки.

В русской лингвокультуре в значении номинации алконост акцентируется необычная внешность птицы, ее качественная характеристика и связь с другими фантастическими птицами. В структуре значения слова алконост появились, по данным русских энциклопедических, этнолингвистических, мифрологических, этимологических исторических, толковых словарей и словарей иностранных слов, следующие семантические компоненты: 'прототип' (вилы' / стратим²), 'птица-сестра' / 'птица-пара' (сирин ${ }^{3}$ ), 'качественная характеристика' ('птица радости', 'сказочная' 'фольклорная'; 'мифическая'; 'святая'), 'внешность' ('разноцветные перья'; 'птица с человеческим (женским) лицом'; 'полуженщина-полуптица'; 'прекрасная'; 'крылья, но человеческие руки'), 'птица со схожими функциями' (страфиль / стратим), 'использование образа' ('народная культура' (живопись, литература); 'древнерусская литература'; 'искусство неоромантизма'), 'символ' ('божий промысел'; 'божье милосердие').

Представленные в исторических словарях и НКРЯ (Основной подкорпус) контексты употребления номинации алконост позволяют сделать вывод, что для носителя языка при характеристике этой франтастической птицы наиболее важными являются следующие семантические компоненты: 'гендер' (преимущественно 'феминность'), 'качественная характеристика' ('мифическая'; 'франтастическая'; 'сказочная'; 'птица радости'; 'волшебная'; 'вдохновляющая'; 'хищная'; 'птица смерти и печали'), 'внешность' ('огненная'), 'способности' ('способность успокаивать море'; 'прекрасный голос'; 'вещая'; 'говорящая'), 'локализация' ('морская'; 'райская'), 'оценка (этическая положительная и отрицательная)', 'связь с другими ффантастическими птицами' ('птица в одном ряду с сирином, әамаюном', жар-птицей ${ }^{\prime}$ )

Отметим, что окказиональные семы в структуре значения номинации алконост связаны с фантастической сущностью птицы, ее необычной окраской и мужским гендером. Проиллюстрируем последний семантический компонент 'маскулинность', встретившийся только в предложении из документа начала XVIII в. и подчеркнутый употреблением дважды личного местоимения 3 лица мужского рода единственного числа: «На морских же волнах гнгзздо алкиона птицы, о неиже повгоствуют: яко егда он на водах морских гнгоздо себго устелет, никогда же буря на морго

\footnotetext{
1 Прим.: Вилы - «женский мифологический персонаж южных славян (...), по ряду признаков сходный с восточнославянской русалкой и западноевропейской богинкой» $[15$, с. 76$]$.

2 Прим.: Стратим - мифическая птица, упоминаемая в Голубиной книге; как и алконост, « «детей производит на океане-море» и при этом обладает властью над погодой; от ударов ее крыл рождаются ветры и подымается буря» $[27$, с. 25].

Зрим.: Сирин - райская птица-дева, образ которой восходит к древнегреческим сиренам; «в русском искусстве С. и алконост - традиционный изобразительный сюжет) $[10$, с. 492].

${ }^{4}$ Прим.: Гамаюн - вещая птица, глашатай богов; «изображали эту птицу с женским лицом и грудью; иногда просто большой птицей, вылетающей из морских глубин» [27, с. 206-207].

5 Прим.: Жар-птица - чудесная птица в восточнославянской сказке; ее золотая окраска и золотая клетка связаны с тем, что «птица прилетает из другого («тридесятого») царства» [14, с. 180-181].
} 
не бывает, донели же он дготи выведет. Политиколепная апофеосис, М., 1709, 20» [20].

На наш взгляд, семы 'вещая' и ее вариации 'вдохновляющая', 'говорящая', могут быть или развитием семы 'прекрасный голос', или заимствованием (наряду с семой 'птица в одном ряду с гамаюном') у лексемы гамаюн, пришедшей в русский язык во второй половине XVI в.: "ОH завораживал и старого и малого, и слова его и певучий, проникновенный голос звучали как музыка. Так, вероятно, пели и эти вещие птицы Сирин и Алконост. [Ф. В. Гладков. Повесть о детстве (1948)]"; "Не говоря, кто меня к нему направил, я с волнением дал ему два маленьких стихотворения, внушенные Сирином, Алконостом и Гамаюном В. Васнецова. [А. А. Блок. Автобиограсрия (1915)]"; "Дева Феврония в белой блузке, черной юбке и кедах бродит по условному лесу, аде прибит огромный рукомойник и стоят кувиины в человеческий рост, и разговаривает с птицами Сирином и Алконостом. [Б. Езерская. Мариинский на сцене мет (2003) // «Вестник США», 2003.08.20]» [12].

Семантические компоненты 'хищная' и 'птица смерти и печали' являются, по нашему мнению, заимствованными у лексемы сирин, появившейся в русском языке не позже XI в., и восходят, в том числе, к мифу о сирене 1 (прототипе сирина): «Солдаты черны, с длинным ромбовидным хвостом, стремительны, мрачно-хищны и вещи, как птица Алконост - птица смерти и печали. [Ю. Казаков. На мурманской банке (1961-1962)]» [12].

Отметим, что по данным НКРЯ (Основной подкорпус) в структуре значения лексем алконост появились семы, связанные с окраской птицы. Предполагаем, что данные компоненты были заимствованы у номинации жар-птица: «Сирин и Алконост» - огненные птицы, чарующие людей волшебными песнями о счастье <..> Там люди в хитонах, в рубашках, голые - $и$ в раю, $u$ в аду, <...>, там Сирин и Алконост, горящие, как жар-цєет... [Ф. В. Гладков. Повесть о детстве (1948)]» [12]

Отметим, что лексемы сирин и гамаюн также подверглись процессу семантического заражения (контаминации) ${ }^{2}$ со стороны номинации алконост, но рассмотрение данного семантического явления не входит в задачи нашей статьи.

В текстах, представленных в НКРЯ (Основной подкорпус), номинация алконост может изменять положительную этическую оценку, харак-

${ }^{1}$ Прим.: Сирена - «в греческой мифологии демонические существа, рождённые рекой Ахелоем и одной из муз»; полуптицы-полуженщины, заманивающие пением моряков на гибель [10, с. 492]

2 Прим.: Процесс семантического заражения (контаминация) - влияние синтагматических связей слова на формирование его значения: «контекстные значения, реализуемые в них, становятся значением слова, и оно вступает в последующие синтагматические связи уже в новом, контекстуально приобретенном значении» [26, c. 123$]$ терную для словарных десиниций (a), на отрицательную (б): а) «<.. > : Людмила Владимировна изображала птицу печали, Сирина, а Любовь Алексеевна - птицу радости, Алконоста. [Н. О. Лосский. Воспоминания: жизнь и философрский путь (1968)]» [11]; б) «Солдаты черны, сдлинным ромбовидным хвостом, стремительны, мрачно-хищны и вещи, как птица Алконост птица смерти и печали. [Ю. Казаков. На мурманской банке (1961-1962)]» [12]. Отметим, что в текстах, представленных в НКРЯ, номинации алконост полностью утрачивает оценку с точки зрения эстетики.

В НКРЯ (Основной подкорпус) мы также нашли пример омонима, это собственное имя Алконост ${ }^{2}$, употребляющееся как название прибора. Данный омоним, по нашему мнению, возник на базе фантастического значения слова: «В больиую дорожную сумку я бросил все наши деньаи, аптечку, свой раухер, блок памяти от «Алконоста» Якова и, наконец, ББГ-камеру. <...> Якову сделали выгородку из стеклоблоков, там он и сидел на пару с «КРК» - сверхмощным раухером, не чета переносному "Алконосту», который был у него на турбазе. [А. Лазарчук. Все, способные держать оружие... (1995)]» [12].

В целом метафоризация не характерна для номинации алконост. Среди прозаических документов, представленных в НКРЯ (Основной подкорпус), мы нашли один вариант метафорического употребления по модели НЕЧТО ЕСТЬ НЕЧТО - 'изображение в виде птицы' («Это была ее спальня, и на том же месте стояла ее кровать, и все так же на стене висел резной икафчик-аптечка с поблекшим Алконостом и Сирином на дверцах, - из него она взяла тогда морфий. [А. Н. Толстой. Хождение по мукам / Книга третья. Хмурое утро (1941)]» [12]), которое активизирует такие семы прямого значения, как 'фантастическая' и 'фольклорная'. Полагаем, что метафора возникла на базе фантастического значения слова.

Метонимический перенос номинации алконост более продуктивен. Среди прозаических документов, представленных в НКРЯ (Основной подкорпус), мы нашли 5 вариантов метонимического употребления лексемы по смежности социальной характеристики или вследствие употребления слова в качестве названия предмета с изображением птицы алконост, которые базируются на фантастическом значении слова:

1) 'прозвище человека' по его месту работь (символистское издательство С. М. Алянского «Алконост» (1918-1923) с соответствующим логотипом) («И через четырехлетие «Опыта» Алконост - С. М. Алянский, «волисполком обезьяний», мытарства и огорчения книжные, бесчисленные, как заседания, прошения Луначарскому, разрыв и мировая с Ильей Ионовым. [А. М. Ремизов. Взвихренная Русь (1917-1924)]” [12]);

2) 'титул (иронический)' по смежности оценки социального статуса ("Я император птиц! - 
восклицал он. - Князь Алконост, хан Гамаюн, непокоренный Буревятник! [В. Аксенов. Новый сладостный стиль (2005)]» [12]);

3) 'название предмета искусства (картины)' т.е. употребление вместо выражения «картина с названием «Птица Алконост»» («Посетили его и «Высочайшие»: <...>, причем Сергей Александрович приобрел «Птицу Алконост», а Павел Александрович прекрасные рисунки к «Купцу Калашникову», что сейчас находятся в Русском музее. [М. В. Нестеров. О пережитом. 1862-1917 гг Воспоминания (1926-1928)]» [12]);

4) 'название организации (книжного издательства)' по соответствующему логотипу издательства с изображением птицы («Издательство "Алконост" связало собою имена Ал. Блока, Андрея Белого, Вяч. Иванова, Иванова-Разумника, А. Ремизова, Анны Радловой, К. Эрберга [М. А. Кузмин. Мечтатели (1921)]» [12]);

5) 'название (ироническое) административной единицы' по смежности оценки социального статуса ( ККаково, приелашают прямо в сердие империи, на ферму "Галифакс», в окрестностях Алконоста, графрство Йорноверблюдо, мальчики и девочки! Раз приглашают, значит, поехали! [В. Аксенов. Новый сладостный стиль (2005)]) [12])
Итак, на основе полученных сведений можно прийти к выводу, что общее значение лексемы алконост изменялось следующим образом: от значения 'мифологическая женщина-птица' развитие одновременно шло в двух направлениях - 'франтастическая птица-женщина' (позже в русской лингвокультуре 'русская фантастическая райская птица') и 'реальная морская птица'. Отнесенность номинации алконост к разряду имен собственных, характерная для мифологии, утрачивается. В то же время наблюдается сохранение проявлений мифологического антропоцентризма в отношении значения 'фантастическая птица-женщина'

Дпя изучаемой номинации в русском языке характерно с одной стороны сужение значения, с другой - его расширение вплоть до ментализации. В русской лингвокультуре, преимущественно, сохранилась амбивалентная этическая оценка птицы, при этом номинация алконост стала оцениваться положительно с точки зрения эстетики. В семантическом плане влияние на лексему алконост оказали номинации еамаюн, сирин и жар-птица.

\section{Литература}

1. Большая Советская энциклопедия: в 30 томах / гл. ред. А. М. Прохоров. 3-е изд. Т.1. М.: Издательство «Советская энциклопедия», 1970. 608 с.

2. Большая энциклопедия. Словарь общедоступных сведений по всем отраслям знания. В 22 т. / под ред. С. Н. Южакова. Т.1. СПб.: Книгоиздательское т-во «Просвещение», 1900.800 с.

3. Бурдон И. Ф. Полный словарь иностранных слов, вошедших в употребление в русском языке, с означением их корней / сост. по лучшим источникам Бурдон и Михельсон. 11-е изд. М.: А. Я. Панафидина, 1907. 476 с

4. Верещагин Е. М., Костомаров В. Г. Национально-культурная семантика русских фразеологизмов // Словари и лингвострановедение: сб. науч. тр. М.: Рус. яз., 1982. С. 89.

5. Дьяченко Г. Полный церковно-славянский словарь (с внесением в него важнейших древнерусских слов и выражений). М.: Типография Вильде, 1898. 1120 с.

6. Ефремов Е. Новый полный словарь иностранных слов, вошедших в русский язык: с указанием происхождения их, ударений, отраслей знания и с расширенной энциклопедической частью / составил по русским и иностранным источникам Е. Ефремов / под ред. проф. И. А. Бодуэна-де-Куртене. Изд. 2-е. М.: Т-во А. А. Левенсон, 1912.605 с.

7. Мартыновский, Ковалевский Новейший полный словотолкователь и объяснитель 150000 иностранных слов. М.: Издание Е. В. Манухиной, 1886. Ч. 1. 274 с.

8. Материалы для словаря древнерусского языка по письменным памятникам / Труд И. И. Срезневского. СПб.: Типография Императорской Академии Наук, 1893. Т. 1.1420 c.

9. Маковский М. М. Сравнительный словарь мифологической символики в индоевропейских языках: Образ мира и миры образов. М.: Гуманит. изд. центр ВЛАДОС, 1996. 416 с

10. Мифологический словарь / гл. ред. Е. М. Мелетинский. М.: Сов. Энциклопедия, 1990. 672 с.

11. Мифы народов мира. Энциклопедия / гл. ред. С. А. Токарев. М.: Издательство «Советская энциклопедия», 1980 $1147 \mathrm{c}$.

12. Национальный корпус русского языка [Электронный ресурc]. URL: http://www.ruscorpora.ru (Дата обращения: 01.09.2019).

13. Объяснительный словарь иностранных слов, вошедших в употребление в русский язык, с объяснением их корней: сост. по словарям: Гейзе, Рейфа и др. / А. Д. Михельсон. 9-е изд. Москва: «Русская тип» А. О. Лютецкого, 1883. $752 \mathrm{c}$.

14. Славянская мифология. Энциклопедический словарь / под ред. В. Я. Петрухина, Т. А. Агапкиной, Л. Н. Виноградовой, С. М. Толстой. М.: Эллис Лак, 1995. 416 с.

15. Славянская мифология. Энциклопедический словарь / под ред. С. М. Толстой, Т. А. Агапкиной, О. В. Беловой, Л. Н. Виноградовой, В. Я. Петрухина. 2-е изд. М.: Междунар. отношения, 2014. 512 с.

16. Славянские древности: Этнолингвистический словарь: В 5-ти томах / под общей ред. Н. И. Толстого. Т.4. М.: Международные отношения, 2009. 656 с.

17. Славянские древности: Этнолингвистический словарь: В 5-ти томах / под общей ред. Н. И. Толстого. Т.1. М. Международные отношения, 1995. 575 с.

18. Словарь Академии Российской, по азбучному порядку расположенный: В 6 т. Ч.1. СПб.: При Императорской Академии Наук, 1806. 1310 c. 
19. Словарь русского языка XI-XVII вв. / гл. редактор С. Г. Бархударов. М.: Издательство «Наука», 1975. Вып. 1. $375 \mathrm{c}$

20. Словарь русского языка XVIII века / АН СССР. Ин-т рус. яз.; Гл. ред.: Ю. С. Сорокин Л.: Наука. Ленингр. отд-ние, 1984. Вып. 1. 224 c. URL: http://feb-web.ru/feb/s/18/slov-abc/ (Дата обращения: 01.09.2019).

21. Словарь современного русского литературного языка: В 17-ти т. (Большой академический словарь, БАС) / Академия Наук СССР, 17. Институт русского языка. Т.1. Москва-Ленинград: Издательство Академии Наук СССР, 1950. 768 с

22. Словарь церковно-славянского и русского языка, составленный вторым отделением Императорской Академии наук: В 4 т. Т. 1. СПб.: Типография при Императорской Академии наук, 1847. 439 с.

23. Толковый словарь живого великорусского языка В. И. Даля. 2-е издание, исправленное и значительно умноженное по рукописям автора. Т. 1. СПб. - М., 1880. 723 с.

24. Фасмер М. Греко-славянские этюды ІІІ. Греческие заимствования в русском языке. СПб.: тип. Имп. АН, 1909. 236 c. URL: http://books.e-heritage.ru/book/10079685 (Дата обращения: 01.09.2019).

25. Фасмер М. Этимологический словарь русского языка / Под редакцией и с предисловием проф. Б. А. Ларина: В 4 томах. 2-е изд., стереотип. Т. 1. М.: Прогресс, 1986. 576 с.

26. Федосеева И. В. Социолингвистические и культурологические аспекты процесса заимствования в российском политическом социолекте 90-х гг. XX в. - начала XXI в.: дис. ... кан. филол. наук. Ставрополь, 2003. 322 с.

27. Шапарова Н. С. Краткая энциклопедия славянской мифологии: Около 1000 статей. М.: ООО «Издательство АСТ»: ООО «Русские словари», 2001.624 с.

28. Этимологический словарь русского языка / автор-составитель Н. М. Шанский. Т.1. Вып. 1. М.: Издательство Московского университета, 1963. $198 \mathrm{c}$.

\section{References}

1. Bol'shaya Sovetskaya entsiklopediya: $v 30$ tomakh (The great soviet encyclopedia). Vol. 1. Moscow: Sovetskaya entsiklopediya, 1970. 608 p. (In Russian)

2. Bol'shaya entsiklopediya. Slovar' obshchedostupnykh svedenii po vsem otraslyam znaniya (The great encyclopedia The dictionary of popular information in all branches of knowledge). In $22 \mathrm{v}$. Vol. 1. / ed by S.N. Yuzhakova. St.Petersburgg Prosveshchenie publ., 1900. 800 p. (In Russian)

3. Burdon I. F. Polnyi slovar' inostrannykh slov, voshedshikh $v$ upotreblenie $v$ russkom yazyke, s oznacheniem ikh kornei (The complete dictionary of foreign words). 11 th ed. M.: A.Ya. Panafidin publ., 1907. 476 p. (In Russian)

4. Vereshchagin E. M., Kostomarov V. G. Natsional'no-kul'turnaya semantika russkikh frazeologizmov (National-cultural semantics of Russian phraseological units) // Slovari i lingvostranovedenie: sb. nauch. tr. Moscow: Russkii yazik publ., 1982. P.89. (In Russian)

5. D'yachenko G. Polnyi tserkovno-slavyanskii slovar' (s vneseniem v nego vazhneishikh drevnerusskikh slov i vyrazhenii) (The complete Church Slavonic dictionary). Moscow: Tipografiya Vil'de publ., 1898. 1120 p. (In Russian)

6. Efremov E. Novyi polnyi slovar' inostrannykh slov, voshedshikh $v$ russkii yazyk: s ukazaniem proiskhozhdeniya ikh, udarenii, otraslei znaniya i s rasshirennoi entsiklopedicheskoi chast'yu (The new complete dictionary of foreign words) / sostavil po russkim i inostrannym istochnikam E. Efremov / pod red. prof. I. A. Boduena-de-Kurtene. Moscow: A. A. Levenson publ., 1912. 605 p. (In Russian)

7. Martynovskii, Kovalevskii Noveishii polnyi slovotolkovatel' i ob"yasnitel' 150000 inostrannykh slov (The latest complete word interpreter and explanator of 150,000 foreign words). Moscow: E. V. Manukhina publ., 1886. Part 1. 274 p. (In Russian)

8. Materialy dlya slovarya drevnerusskogo yazyka po pis'mennym pamyatnikam (Materials for the dictionary of the Old Russian language on written monuments) / Trud I. I. Sreznevskogo. St. Petersburg: Tipografiya Imperatorskoi Akademii Nauk, 1893. Vol. 1. 1420 p. (In Russian)

9. Makovskii M. M. Sravnitel'nyi slovar' mifologicheskoi simvoliki v indoevropeiskikh yazykakh: Obraz mira i miry obrazov (The comparative dictionary of mythological symbolics in the Indo-European languages). Moscow: VLADOS publ., 1996. 416 p. (In Russian)

10. Mifologicheskii slovar' (The mythological dictionary) / ed by E. M. Meletinskii. Moscow: Sovetskaya Entsiklopediya publ., 1990. 672 p. (In Russian)

11. Mify narodov mira. Entsiklopediya (Myths of the peoples of the world. Encyclopedia) / ed by S. A. Tokarev. Moscow: Sovetskaya Entsiklopediya publ., 1980. 1147 p. (In Russian)

12. Natsional'nyi korpus russkogo yazyka (The National Corps of the Russian language) URL: http://www.ruscorpora.ru (Accessed: 01.09.2019). (In Russian)

13. Ob»yasnitel'nyi slovar' inostrannykh slov, voshedshikh $v$ upotreblenie $v$ russkii yazyk, s ob» yasneniem ikh kornei: Sost po slovaryam: Geize, Reifa i dr. (The explanatory dictionary of foreign words). Moscow: A. O. Lyutetskii publ., 1883. 752 p. (In Russian)

14. Slavyanskaya mifologiya. Entsiklopedicheskii slovar' (The Slavic mythology. The encyclopedic dictionary) / ed by V. Ya. Petrukhina, T. A. Agapkina, L. N. Vinogradova, S. M. Tolstaya. Moscow: Ellis Lak publ., 1995. 416 p. (In Russian)

15. Slavyanskaya mifologiya. Entsiklopedicheskii slovar' (The Slavic mythology. The encyclopedic dictionary) / ed by S. M. Tolstya, T. A. Agapkina, O. V. Belova, L. N. Vinogradova, V. Ya. Petrukhina. 2nd ed. Moscow: Mezhdunarodnie otnosheniya publ., 2014. 512 p. (In Russian)

16. Slavyanskie drevnosti: Etnolingvisticheskii slovar' (The Slavic antiquities: The ethnolinguistic dictionary): In 5 volumes / ed by N. I. Tolstoi. Moscow: Mezhdunarodnie otnosheniya publ., 2009. Vol. 4. 656 p. (In Russian)

17. Slavyanskie drevnosti: Etnolingvisticheskii slovar' (The Slavic antiquities: The ethnolinguistic dictionary): In 5 volumes / ed by N. I. Tolstoi. Moscow: Mezhdunarodnie otnosheniya publ., 1995. Vol. 1. 575 p. (In Russian)

18. Slovar' Akademii Rossiiskoi, po azbuchnomu poryadku raspolozhennyi (The dictionary of the Russian Academy): In 6 vol. St. Petersburg: Pri Imperatorskoi Akademii Nauk, 1806. Part 1.1310 p. (In Russian) 
19. Slovar' russkogo yazyka XI-XVII vv. (The dictionary of the Russian language of the XI-XVII centuries) / ed by S. G. Barkhudarov. Moscow: Nauka publ., 1975. Issue. 1. 375 p. (In Russian)

20. Slovar' russkogo yazyka XVIII veka (The dictionary of the Russian language of the XVIII century) / URL: http://feb-web $\mathrm{ru} / \mathrm{feb} / \mathrm{s}$ 18/slov-abc/ (Accessed: 01.09.2019). (In Russian)

21. Slovar' sovremennogo russkogo literaturnogo yazyka (The dictionary of the modern Russian literary language): In 17-ti v. (Bol'shoi akademicheskii slovar', BAS). Moskva-Leningrad: SA USSR publ., 1950. Vol. 1. 768 p. (In Russian)

22. Slovar' tserkovno-slavyanskogo i russkogo yazyka, sostavlennyi vtorym otdeleniem Imperatorskoi Akademii nauk (The dictionary of the Church Slavonic and the Russian language): In 4 vol. St.Petersburg: Tipografiya pri Imperatorskoi Akademii nauk, 1847. Vol. 1. 439 p. (In Russian)

23. Tolkovyi slovar' zhivogo velikorusskogo yazyka V. I. Dalya (The explanatory dictionary of the living Great Russian language). St. Petersburg-Moscow, 1880. Vol. 1. 723 p. (In Russian)

24. Fasmer M. Greko-slavyanskie etyudy III. Grecheskie zaimstvovaniya v russkom yazyke (The Greek-Slavic Etudes III. The Greek borrowings in the Russian language) St. Petersburg, 1909. 236 p. URL: http://books.e-heritage.ru/book/10079685 (Accessed: 01.09.2019). (In Russian)

25. Fasmer M. Etimologicheskii slovar' russkogo yazyka (The etymological dictionary of the Russian language) / ed by B. A. Larin: In 4 volumes. Moscow: Progress, 1986. Vol. 1. 576 p. (In Russian).

26. Fedoseeva I. V. Sotsiolingvisticheskie i kul'turologicheskie aspekty protsessa zaimstvovaniya $v$ rossiiskom politicheskom sotsiolekte 90-kh gg. XX v. - nachala XXI v. (Sociolinguistic and cultural aspects of the borrowing process in the Russian political sociolect of the 90 s. $X X$ century - beginning of the XXI century): thesis. Stavropol', 2003. 322 p. (In Russian)

27. Shaparova N. S. Kratkaya entsiklopediya slavyanskoi mifologii (The brief encyclopedia of the Slavic mythology): Okolo 1000 statei. Moscow: 000 «Izdatel'stvo AST»: OOO «Russkie slovari», 2001.624 p. (In Russian)

28. Etimologicheskii slovar' russkogo yazyka (The etymological dictionary of the Russian language). Moscow: MSU publ., 1963. Vol. 1. Iss. 1. 198 p. (In Russian)

\section{Сведения об авторе}

Зубкова Елена Николаевна - аспирант кафедры русского языка гуманитарного института Северо-Кавказского фредерального университета (Ставрополь) / helen_zubkova@mail.ru

\section{Information about the author}

Zubkova Elena - postgraduate student, Chair of Russian, Institute of Humanities, North-Caucasus Federal University (Stavropol) / helen_zubkova@mail.ru 